\title{
Qualidade físico-química e microbiológica do leite in natura: revisão sistemática
}

Esta revisão sistemática objetivou identificar os artigos científicos que abordaram a qualidade físico-química e microbiológica do leite in natura refrigerado, bem como as formas de coleta, armazenamento e análises laboratoriais realizadas neste alimento entre os anos de 2006 a 2016 . Tomando-se como base o Portal de Periódicos da CAPES, utilizou-se como descritores 'leite', 'leite' e 'qualidade', 'leite' e 'qualidade microbiológica', 'leite cru' e 'qualidade microbiológica', 'leite cru' e 'qualidade microbiológica físico-química', 'leite cru' e 'físico-química' e 'milk' e 'microbiology'. Como critério de inclusão, foram utilizados os artigos disponibilizados com o texto completo e gratuito nas bases pesquisadas. A busca inicial resultou em 1.743 artigos. Após a leitura dos resumos 50 artigos foram selecionados para leitura integral. Destes 24 foram analisados e 14 destes discutidos neste artigo. Conclui-se que a maior parte das amostras de leite analisadas nos artigos estavam em desacordo com a legislação ou com a literatura, possivelmente pela falta de higiene durante a ordenha ou armazenamento, no qual todas pesquisas basearam-se na coleta de leite em tanques de refrigeração. A implementação de boas práticas de higiene na ordenha gera um leite de qualidade, garante o bem-estar animal e melhora a lucratividade da produção.

Palavras-chave: Leite cru; Análises laboratoriais; Armazenamento; Coleta; Parâmetros.

\section{Physical-chemical and microbiological quality of milk in natura: systematic review}

\begin{abstract}
This systematic review aimed to identify the scientific articles that approached the physico-chemical and microbiological quality of the refrigerated fresh milk, as well as the forms of collection, storage and laboratory analyzes carried out in this food between the years 2006 to 2016. Taking as a base the CAPES Journal Porta was used as descriptors 'milk', 'milk' and 'quality', 'milk' and 'microbiological quality', 'raw milk' and 'microbiological quality', 'raw milk' and 'quality' microbiological physicochemical ',' raw milk 'and' physico-chemical 'and' milk 'and' microbiology '. As inclusion criterion, the articles were made available with the complete and free text in the searched databases. The initial search resulted in 1,743 articles. After reading the abstracts 50 papers were selected for full reading. Of these 24 were analyzed and 14 of these are discussed in this article. It was concluded that most of the milk samples analyzed in the articles were in disagreement with legislation or literature, possibly due to lack of hygiene during milking or storage, in which all surveys were based on milk collection in cooling. The implementation of good hygiene practices in milking generates quality milk, guarantees animal welfare and improves the profitability of production.
\end{abstract}

Keywords: Raw milk; Laboratory analysis; Storage; Collect; Parameters.

Topic: Microbiologia Agrícola e Ambiental

Reviewed anonymously in the process of blind peer.

Mônica Jachetti Maciel (id

Universidade do Vale do Taquari, Brasil http://lattes.cnpq.br/2575088289818885 http://orcid.org/0000-0002-6863-2181

monicajm@univates.br

Cynthia de Freitas Birkheuer (iD

Universidade do Vale do Taquari, Brasil

http://lattes.cnpq.br/8536621031100499

http://orcid.org/0000-0002-1752-1748

cynthia.birkheuer@univates.br

Claudete Rempel

Universidade do Vale do Taquari, Brasil

http://lattes.cnpq.br/8340497822227462

http://orcid.org/0000-0001-8573-0237

crempel@univates.br

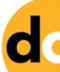

DOI: 10.6008/CBPC2237-9290.2018.001.0003
Received: 16/01/2018

Approved: 28/04/2018

\section{Referencing this:}

MACIEL, M. J.; BIRKHEUER, C. F.; REMPEL, C.. Qualidade físico-química e microbiológica do leite in natura: revisão sistemática. Natural Resources, v.8, n.1, p.17-30, 2018. DOI:

http://doi.org/10.6008/CBPC2237-9290.2018.001.0003 


\section{INTRODUÇÃO}

Segundo dados do IBGE (2016), a região Sul é a maior produtora de leite no Brasil, com produção anual de 12,32 bilhões de litros, representando $35,2 \%$ da produção nacional. O Rio Grande do Sul apresentou a maior produtividade dentre os estados do Sul, representando cerca de 3.073 litros/vaca/ano (IBGE, 2016). O leite ocupa um grande espaço na economia mundial e tem importância social que é praticada em quase todo o país em aproximadamente um milhão de propriedades rurais (LANGONI et al., 2011).

Este é um dos alimentos mais completos em termos nutricionais pois possui características que o torna fundamental para dieta humana e constitui um excelente substrato para o desenvolvimento de microrganismos, inclusive os patogênicos. Por isso, a qualidade do leite é uma constante preocupação a todos (LEITE et al., 2000; TIMM et al., 2003).

A má qualidade microbiológica do leite in natura está relacionada a fatores como mastite, higiene na ordenha, manutenção inadequada dos equipamentos (refrigeradores e ordenhadeiras), mão de obra desqualificada, entre outros fatores (VALLIN et al., 2009; BRASIL et al., 2012). A composição físico-química deste alimento, como gordura, proteína, sólidos totais, lactose e minerais, está relacionada a fatores como raça e fisiologia do animal (BRASIL et al., 2012). Os microrganismos também podem provocar alterações físico-químicas no leite, que interferem na durabilidade, alteram as características sensoriais e causam a perda de rendimento na produção de derivados lácteos (MARTINS et al., 2013).

O produtor passou a produzir um leite com qualidade controlada e de acordo com as exigências das indústrias, com isso, foram implementadas normas nacionais de qualidade do leite cru pelo Ministério da Agricultura, Pecuária e Abastecimento (MAPA) por meio da Instrução Normativa (IN) n 62/2011. Esta legislação determina normas na produção, identidade e qualidade de tipos de leites, além de regulamentar a coleta do leite no refrigerador e seu transporte à granel (BRASIL, 2011).

Diante do exposto, este trabalho teve como objetivo realizar uma revisão sistemática com a finalidade de identificar artigos científicos referentes à temática 'leite in natura', frente aos aspectos relacionados com a coleta, armazenamento, qualidade, análises físico-químicas e microbiológicas do leite.

\section{METODOLOGIA}

Esta revisão sistemática para verificar diversas características do leite in natura descritas na literatura científica. Foram considerados todos artigos científicos com até 10 anos de publicação (2006-2016), disponíveis na íntegra e de forma gratuita no Portal de Periódicos da CAPES. Os descritores utilizados foram: 'leite', 'leite' and 'qualidade', 'leite' and 'qualidade microbiológica', 'leite cru' and 'qualidade microbiológica', 'leite cru' and 'qualidade microbiológica físico-química', 'leite cru' and 'físico-química' e 'milk' and 'microbiology'. Não houve restrição de língua ou delineamento de pesquisa (Figura 1).

A análise dos artigos científicos foi dividida em quatro etapas: a primeira foi a leitura do título dos artigos (1.743), dos quais foram selecionados aqueles que continham os descritores citados acima, após esta leitura, foram excluídos os artigos que apresentavam repetições (23); na segunda etapa, foram selecionados 
os artigos (50), a partir da leitura dos resumos, que mencionavam procedimentos de coleta, armazenamento, qualidade, análises microbiológicas e físico-químicas e os resultados do leite in natura, seguindo os padrões exigidos pela respectiva legislação da pesquisa; na terceira etapa, foram lidos e avaliados os artigos completos (24), conforme os assuntos citados acima, bem como a quantificação de bactérias mesófilas e psicrotróficas por meio da diluição decimal e plaquemento, teor de acidez, determinação de pH, densidade relativa, quantidade de gordura, proteína, lactose, extrato seco desengordurado, assim como os resultados destas análises foram analisados; e a última etapa foi a seleção dos artigos (14) que se enquadravam no escopo desta pesquisa para análise e discussão.

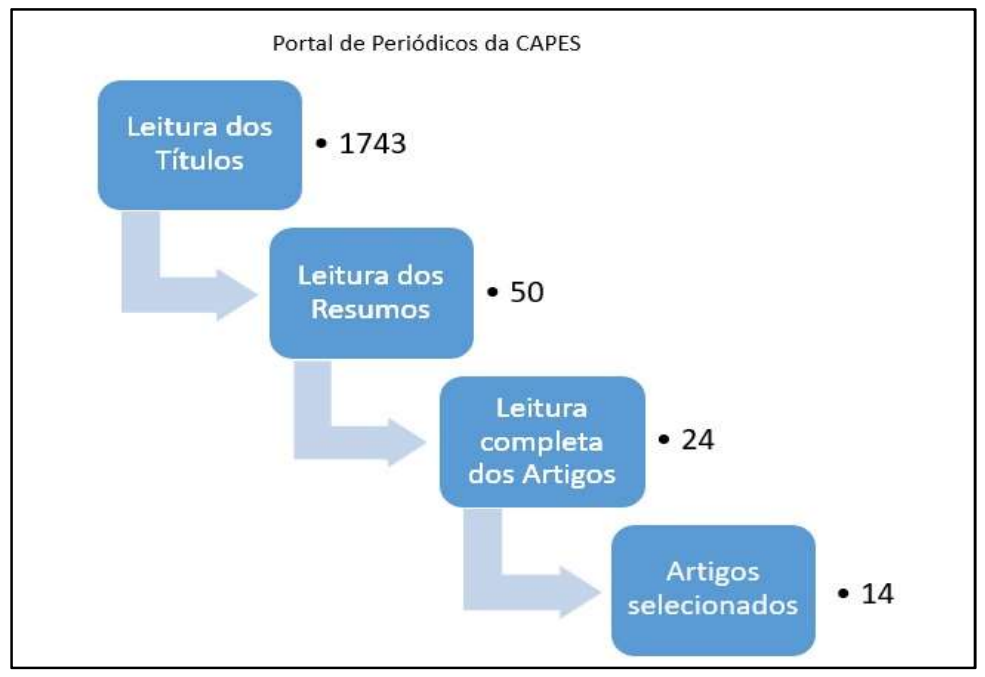

Figura 1: Fluxograma das etapas realizadas para seleção dos artigos de interesse.

Excluíram-se os artigos científicos que abordavam outros tipos de leites, como o A, B ou C, coletas realizadas em caminhões tanques, já que a pesquisa é realizada apenas com a coleta diretamente no tanque de refrigeração, ou então análise microbiológica de outros tipos de microrganismos se não micro-organismos mesófilos e psicrotróficos. A análise dos artigos selecionados levou em conta os aspectos presentes como a coleta, armazenagem, qualidade, análises físico-químicas e microbiológicas do leite in natura refrigerado realizados pelos autores.

\section{RESULTADOS}

A revisão sistemática partiu da análise de 1.743 artigos publicados. A segunda etapa, que consistiu na leitura dos resumos destes artigos foram selecionadas 50 pesquisas científicas, tendo sido excluídos os que não apresentavam metodologias semelhantes as estudadas. Posteriormente foram lidos os textos completos das 50 pesquisas científicas, tendo maior atenção maior as metodologias que tiveram como base a Instrução Normativa (IN) n 62/2011, do MAPA. Após a avaliação, selecionou-se para análise 14 artigos (Quadro 1), representando 0,91\% do total de artigos publicados na base de dados consultada.

Quadro 1: Artigos científicos selecionados e características avaliadas.

\begin{tabular}{|l|l|l|l|l|}
\hline Título & Objetivos & Metodologias & Resultados \\
\hline $\begin{array}{l}\text { Qualidade do leite cru } \\
\text { dos tanques de expansão } \\
\text { individuais e coletivos de }\end{array}$ & $\begin{array}{l}\text { Avaliar a qualidade } \\
\text { microbiológica e físico-química } \\
\text { e verificar a ocorrência de }\end{array}$ & $\begin{array}{l}\text { Coletou-se } 36 \text { amostras de } \\
\text { leite cru de 12 tanques de } \\
\text { expansão em três }\end{array}$ & $\begin{array}{l}\text { Constatou-se que 80\% das } \\
\text { amostras não atenderam } \\
\text { aos padrões estabelecidos }\end{array}$ & $\begin{array}{l}\text { Martins et al. } \\
\text { (2013) }\end{array}$ \\
\hline
\end{tabular}




\begin{tabular}{|c|c|c|c|c|}
\hline Título & Objetivos & Metodologias & Resultados & Referência \\
\hline $\begin{array}{l}\text { um laticínio do município } \\
\text { de Rio Pomba, MG - um } \\
\text { estudo de caso. }\end{array}$ & $\begin{array}{l}\text { substâncias inibidoras do } \\
\text { crescimento microbiano no } \\
\text { leite cru procedente dos } \\
\text { tanques de expansão } \\
\text { individuais e coletivos de uma } \\
\text { indústria de laticínios. }\end{array}$ & $\begin{array}{l}\text { repetições. Foram } \\
\text { determinadas as } \\
\text { contagens de micro- } \\
\text { organismos mesófilos } \\
\text { aeróbios, psicrotróficos e } \\
\text { psicrotróficos } \\
\text { proteolíticos. Também foi } \\
\text { determinada a contagem } \\
\text { de células somáticas, a } \\
\text { ocorrência de pus e de } \\
\text { substâncias inibidoras do } \\
\text { crescimento microbiano, } \\
\text { além da composição físico- } \\
\text { química do leite. }\end{array}$ & $\begin{array}{l}\text { pela Instrução Normativa } \\
\mathrm{n}^{\circ} 51 / 2002 \text {, devido a } \\
\text { contagem de micro- } \\
\text { organismos mesófilos } \\
\text { aeróbios e de células } \\
\text { somáticas estarem acima } \\
\text { de } 7,5 \times 10^{5} \mathrm{UFC} / \mathrm{mL} \text {, } \\
\text { além de ser constatada a } \\
\text { presença de pus e de } \\
\text { substâncias inibidoras do } \\
\text { crescimento microbiano } \\
\text { em algumas amostras. }\end{array}$ & $\begin{array}{l}\text { Rev. Inst. Laticínios } \\
\text { Cândido Tostes }\end{array}$ \\
\hline $\begin{array}{l}\text { Qualidade do leite cru } \\
\text { refrigerado estocado por } \\
\text { diferentes períodos. }\end{array}$ & $\begin{array}{l}\text { Avaliar a qualidade do leite cru } \\
\text { refrigerado estocado por } \\
\text { diferentes períodos. }\end{array}$ & $\begin{array}{l}\text { As coletas foram } \\
\text { realizadas acompanhando } \\
\text { o período de } \\
\text { armazenamento do leite } \\
\text { por zero, } 24,48 \text { e } 72 \\
\text { horas, perfazendo um } \\
\text { total de } 40 \text { amostras. A } \\
\text { contagem de células } \\
\text { somáticas foi realizada por } \\
\text { meio de citometria de } \\
\text { fluxo pelo equipamento } \\
\text { Fossomatic 5000 Basico. A } \\
\text { contagem bacteriana total } \\
\text { (CBT) foi realizada por } \\
\text { meio do equipamento } \\
\text { Bactoscan FCO, cuja } \\
\text { análise baseia-se na } \\
\text { citometria de fluxo. A } \\
\text { análise de resíduos de } \\
\text { antibióticos foi realizada } \\
\text { em todas as amostras por } \\
\text { meio do DELVOTEST. }\end{array}$ & $\begin{array}{l}\text { Os valores encontrados } \\
\text { para a CCS e composição } \\
\text { centesimal atendem aos } \\
\text { padrões exigidos pela } \\
\text { legislação brasileira. A } \\
\text { CBT apresentou valores } \\
\text { elevados sendo } \\
\text { necessária a implantação } \\
\text { de boas práticas na } \\
\text { obtenção e conservação } \\
\text { do leite cru refrigerado. } \\
\text { Não foi detectada a } \\
\text { presença de resíduos de } \\
\text { antibióticos nas amostras } \\
\text { analisadas. }\end{array}$ & $\begin{array}{l}\text { Santos et al. (2008) } \\
\text { Rev. Inst. Latic. } \\
\text { Cândido Tostes }\end{array}$ \\
\hline $\begin{array}{l}\text { Avaliação do tempo de } \\
\text { armazenamento sobre } \\
\text { parâmetros de qualidade } \\
\text { do leite cru refrigerado. }\end{array}$ & $\begin{array}{l}\text { Avaliar a presença de micro- } \\
\text { organismos psicrotróficos e } \\
\text { psicrotróficos proteolíticos e o } \\
\text { índice de } \\
\text { caseinomacropeptídeo (CMP) } \\
\text { em amostras de leite cru } \\
\text { refrigerado coletadas na região } \\
\text { Sudoeste do Estado de Goiás. }\end{array}$ & $\begin{array}{l}\text { As amostras de leite cru } \\
\text { refrigerado foram obtidas } \\
\text { diretamente de } 10 \\
\text { tanques de expansão } \\
\text { individuais. As coletas } \\
\text { foram realizadas com zero, } \\
24,48 \text { e } 72 \text { horas de } \\
\text { armazenamento, } \\
\text { perfazendo um total de } 40 \\
\text { amostras. Foi realizada a } \\
\text { contagem padrão em } \\
\text { placas de micro- } \\
\text { organismos psicrotróficos, } \\
\text { psicrotróficos proteolíticos } \\
\text { e contagem de } \\
\text { Pseudomonas spp. Acidez } \\
\text { titulável e o índice de CMP } \\
\text { também foram } \\
\text { determinados. }\end{array}$ & $\begin{array}{l}\text { A temperatura do leite } \\
\text { cru refrigerado ao longo } \\
\text { do tempo de } \\
\text { armazenamento não } \\
\text { influenciou os parâmetros } \\
\text { avaliados. A acidez } \\
\text { titulável atendeu aos } \\
\text { padrões exigidos pela } \\
\text { Instrução Normativa n } \\
\text { 51/2002. A média das } \\
\text { contagens de micro- } \\
\text { organismos psicrotróficos, } \\
\text { psicrotróficos } \\
\text { proteolíticos e } \\
\text { Pseudomonas spp. foi } \\
\text { alta, e estes não } \\
\text { apresentaram interação } \\
\text { com o índice de CMP. } \\
\text { Embora tenha sido } \\
\text { observada a presença de } \\
\text { CMP em algumas } \\
\text { amostras de leite cru } \\
\text { refrigerado. }\end{array}$ & $\begin{array}{l}\text { Santos et al. (2009) } \\
\text { Rev. Inst. Latic. } \\
\text { "Cândido Tostes" }\end{array}$ \\
\hline $\begin{array}{l}\text { Produção e qualidade do } \\
\text { leite de vacas da raça } \\
\text { Holandesa em função da } \\
\text { estação do ano e ordem } \\
\text { de parto. }\end{array}$ & $\begin{array}{l}\text { Avaliar o efeito da ordem de } \\
\text { lactação e estação do ano ao } \\
\text { parto sobre a produção e } \\
\text { qualidade do leite de vacas da } \\
\text { raça Holandesa. }\end{array}$ & $\begin{array}{l}\text { A análise da percentagem } \\
\text { de gordura e proteína foi } \\
\text { feita pela técnica de } \\
\text { leitura de absorção } \\
\text { infravermelha em } \\
\text { equipamento } \\
\text { automatizado Bentley } \\
2000^{\circledR} \text {, enquanto que, } \\
\text { para análise da CCS, } \\
\text { utilizou-se equipamento } \\
\text { com citometria de fluxo } \\
\text { Somacount } 500^{\circledR} \text {. }\end{array}$ & $\begin{array}{l}\text { Vacas de 3a e 4a lactação } \\
\text { foram mais produtivas } \\
\text { devido ao completo } \\
\text { desenvolvimento da } \\
\text { glândula mamária e } \\
\text { crescimento corporal. O } \\
\text { ECS aumentou com a } \\
\text { elevação do número de } \\
\text { lactações devido ao } \\
\text { contato com agentes } \\
\text { patogênicos à medida que } \\
\text { os animais têm uma idade } \\
\text { mais avançada. Lactações } \\
\text { iniciadas na primavera } \\
\text { apresentaram a menor }\end{array}$ & $\begin{array}{l}\text { Souza et al. (2010) } \\
\text { Rev. Bras. Saúde } \\
\text { Prod. Animal }\end{array}$ \\
\hline
\end{tabular}




\begin{tabular}{|c|c|c|c|c|}
\hline Título & Objetivos & Metodologias & Resultados & Referência \\
\hline & & & $\begin{array}{l}\text { produção de leite pelo } \\
\text { estresse calórico que os } \\
\text { animais sofreram no pico } \\
\text { de lactação, de modo a } \\
\text { comprometer a produção } \\
\text { de leite dessa lactação. } \\
\text { ECS e teores de gordura e } \\
\text { proteína não variaram em } \\
\text { função da época de } \\
\text { parição. }\end{array}$ & \\
\hline $\begin{array}{l}\text { Melhoria da qualidade do } \\
\text { leite a partir da } \\
\text { implantação de boas } \\
\text { práticas de higiene na } \\
\text { ordenha em } 19 \\
\text { municípios da região } \\
\text { central do Paraná. }\end{array}$ & $\begin{array}{l}\text { Avaliar a eficiência da } \\
\text { implantação de Boas Práticas } \\
\text { na ordenha na ordenha, } \\
\text { simples e baratas, que } \\
\text { pudessem ser facilmente } \\
\text { introduzidas pelos produtores } \\
\text { de leite. }\end{array}$ & $\begin{array}{l}\text { Os parâmetros de } \\
\text { qualidade considerados } \\
\text { foram a contagem de } \\
\text { células somáticas (CCS), } \\
\text { indicativo de sanidade da } \\
\text { glândula mamária, e a } \\
\text { contagem bacteriana total } \\
\text { (CBT), indicativo de } \\
\text { higiene de ordenha. Foram } \\
\text { analisadas } 46 \text { amostras de } \\
\text { leite cru de } 19 \text { municípios } \\
\text { da região central do } \\
\text { Paraná, sendo } 32 \text { (69,57\%) } \\
\text { de propriedades com } \\
\text { ordenha manual e } 14 \\
\text { (30,43\%) com ordenha } \\
\text { mecânica. }\end{array}$ & $\begin{array}{l}\text { Após a implantação das } \\
\text { práticas houve uma } \\
\text { redução média de } 87,90 \% \\
\text { na CBT nas propriedades } \\
\text { com ordenha manual e } \\
86,99 \% \text { nas propriedades } \\
\text { com ordenha mecânica. } \\
\text { Com relação a CCS, a } \\
\text { redução média foi de } \\
\text { 33,94\% em propriedades } \\
\text { com ordenha manual e } \\
51,85 \% \text { em propriedades } \\
\text { com ordenha mecânica. }\end{array}$ & $\begin{array}{l}\text { Vallin et al. (2009) } \\
\text { Semina: Ciências } \\
\text { Agrárias }\end{array}$ \\
\hline $\begin{array}{l}\text { Qualidade microbiológica } \\
\text { de leite cru refrigerado e } \\
\text { fatores associados. }\end{array}$ & $\begin{array}{l}\text { Realizar um estudo sobre a } \\
\text { incidência de alguns fatores } \\
\text { que influenciam a qualidade do } \\
\text { leite cru resfriado estocado e } \\
\text { submetido à coleta a granel. }\end{array}$ & $\begin{array}{l}\text { Para avaliação das } \\
\text { condições microbiológicas } \\
\text { do leite cru e estudo de } \\
\text { alguns dos fatores que } \\
\text { influenciam sua qualidade, } \\
\text { foram analisadas } 31 \\
\text { propriedades leiteiras. } \\
\text { Realizou-se análises de } \\
\text { micro-organismos } \\
\text { aeróbios mesófilos, } \\
\text { coliformes, coliformes } \\
\text { termotolerantes e de } \\
\text { bolores e leveduras. }\end{array}$ & $\begin{array}{l}\text { Entre as amostras } \\
\text { analisadas, } 25,80 \% \text { (para } \\
\text { aeróbios mesófilos) e } \\
19,35 \% \text { (para coliformes a } \\
35^{\circ} \mathrm{C} \text { ) apresentaram } \\
\text { contagens acima do } \\
\text { padrão vigente pela } \\
\text { legislação e } 58,06 \% \\
\text { possuíam coliformes } \\
\text { termotolerantes. } \\
\text { Verificou-se que } 64,51 \% \\
\text { das amostras } \\
\text { apresentaram contagem } \\
\text { de bolores e leveduras } \\
\text { acima de } 100 \text { UFC/mL. }\end{array}$ & $\begin{array}{l}\text { Citadin et al. (2009) } \\
\text { Rev. Bras. Saúde } \\
\text { Prod. Animal }\end{array}$ \\
\hline $\begin{array}{l}\text { Avaliação da qualidade } \\
\text { microbiológica e físico- } \\
\text { química do leite cru } \\
\text { refrigerado produzido na } \\
\text { região } \\
\text { de Ivaiporã, Paraná }\end{array}$ & $\begin{array}{l}\text { Avaliar parâmetros } \\
\text { microbiológicos e físico- } \\
\text { químicos do leite cru } \\
\text { refrigerado produzido em } 99 \\
\text { propriedades. }\end{array}$ & $\begin{array}{l}99 \text { amostras de leite cru } \\
\text { refrigerado analisadas } \\
\text { Contagem de Células } \\
\text { Somáticas (CCS) e } \\
\text { composição centesimal. } \\
\text { Coletados } 40 \text { mL de leite } \\
\text { em recipientes plásticos } \\
\text { para análise por citometria } \\
\text { de fluxo (SOMACOUNT }{ }^{\circledR} \text { - } \\
\text { 500, Bentley Instruments) } \\
\text { para CCS e por } \\
\text { infravermelho (BENTLEY- } \\
2000 \text { ) para análises de } \\
\text { percentual de gordura, } \\
\text { proteína, lactose e Sólidos } \\
\text { Não Gordurosos (SNG). } \\
\text { Para a CBT também foram } \\
\text { colhidos } 40 \text { mL de leite, } \\
\text { para análise por citometria } \\
\text { de fluxo (BENTLEY). As } \\
\text { análises de acidez } \\
\text { titulável, alizarol } 72 \% \text {, } \\
\text { fervura, densidade relativa } \\
\text { à } 15{ }^{\circ} \text { C, índice crioscópico } \\
\text { (crioscópio eletrônico } \\
\text { digital) e peroxidase foram } \\
\text { realizadas em } 74 \text { das } 99 \\
\text { amostras. Essas } 74 \\
\text { amostras foram coletadas } \\
\text { em "bags" estéreis, } \\
\text { mantidas sob refrigeração } \\
\text { e enviadas ao Laboratório }\end{array}$ & $\begin{array}{l} \\
\text { Foram observadas } \\
\text { amostras fora do padrão } \\
\text { vigente na época para } \\
\text { todas as análises } \\
\text { determinadas pela } \\
\text { legislação: alizarol } 72 \% \\
\text { (63,38\%), acidez titulável } \\
\text { (54,05\%), índice } \\
\text { crioscópico (8,10\%), } \\
\text { densidade (5,40\%), } \\
\text { gordura (17,17\%), } \\
\text { proteína total (14,14\%), } \\
\text { SNG (26,26\%), CCS } \\
\text { (17,17\%) e CBT (54,08). } \\
\text { Foram observadas } \\
\text { fraudes por adição de } \\
\text { água e desnate. }\end{array}$ & $\begin{array}{l}\text { Ribeiro Júnior et al. } \\
\text { (2013) } \\
\text { Rev. Inst. Laticínios } \\
\text { Cândido Tostes }\end{array}$ \\
\hline
\end{tabular}




\begin{tabular}{|c|c|c|c|c|}
\hline Título & Objetivos & Metodologias & Resultados & Referência \\
\hline & & $\begin{array}{l}\text { de Inspeção de Produtos } \\
\text { de Origem Animal para } \\
\text { análise (IN 68/2011). O pH } \\
\text { aferido (pHmetro digital HI } \\
8424 \text { - Hanna) e a } \\
\text { condutividade elétrica (HI } \\
3733 \text { - Hanna). }\end{array}$ & & \\
\hline $\begin{array}{l}\text { Avaliação da qualidade } \\
\text { do leite cru em função do } \\
\text { tipo de ordenha e das } \\
\text { condições de transporte } \\
\text { e armazenamento. }\end{array}$ & $\begin{array}{l}\text { Avaliar a qualidade do leite em } \\
\text { função do tipo de ordenha e } \\
\text { das condições de transporte e } \\
\text { armazenamento. }\end{array}$ & $\begin{array}{l}\text { Entre dezembro de } 2010 \text { a } \\
\text { maio de } 2011 \text {, foram } \\
\text { coletadas amostras de } \\
\text { leite in natura diretamente } \\
\text { dos rebanhos leiteiros e de } \\
\text { leite cru refrigerado } \\
\text { armazenado em tanques } \\
\text { de expansão, tanques } \\
\text { isotérmicos e silos } \\
\text { industriais. As análises } \\
\text { eletrônicas (CCS, CBT e } \\
\text { composição centesimal) } \\
\text { foram realizadas no } \\
\text { Laboratório de Qualidade } \\
\text { do Leite. }\end{array}$ & $\begin{array}{l}\text { A ordenha manual } \\
\text { resultou em leite in } \\
\text { natura e leite cru } \\
\text { refrigerado de melhor } \\
\text { qualidade. O leite } \\
\text { armazenado em silos } \\
\text { industriais apresentou } \\
\text { maior CBT comparado ao } \\
\text { leite armazenado em } \\
\text { tanque isotérmico, no } \\
\text { entanto, ambos } \\
\text { apresentaram altas } \\
\text { contagens microbianas. }\end{array}$ & $\begin{array}{l}\text { Brasil et al. (2012) } \\
\text { Rev. Inst. Latic. } \\
\text { "Cândido Tostes" }\end{array}$ \\
\hline $\begin{array}{l}\text { Qualidade do leite de } \\
\text { propriedades familiares } \\
\text { praticantes de integração } \\
\text { lavoura-pecuária em } \\
\text { função do uso do solo. }\end{array}$ & $\begin{array}{l}\text { Investigar o uso do solo em } \\
\text { propriedades familiares (PF) } \\
\text { manejadas sob integração } \\
\text { lavoura-pecuária (ILP) em bacia } \\
\text { hidrográfica e relacionar com a } \\
\text { qualidade do leite. }\end{array}$ & $\begin{array}{l}\text { A coleta se constituiu de } \\
\text { uma alíquota de } 40 \text { mL de } \\
\text { leite retirada do tanque } \\
\text { refrigerador de leite de } \\
\text { cada PF, seguindo } \\
\text { procedimentos descritos } \\
\text { na Instrução Normativa N } \\
\text { 51/2002. } \\
\text { Os frascos contendo as } \\
\text { amostras de leite foram } \\
\text { armazenados em caixa } \\
\text { isotérmica, até chegarem } \\
\text { ao laboratório de Serviço } \\
\text { de Análises de Rebanhos } \\
\text { Leiteiros da Universidade } \\
\text { de Passo Fundo (Sarle- } \\
\text { UPF). A determinação da } \\
\text { composição química (teor } \\
\text { de gordura, proteína e } \\
\text { sólidos não gordurosos) } \\
\text { deu-se pela leitura de uma } \\
\text { amostra de leite cru. O } \\
\text { equipamento utilizado foi } \\
\text { um Bentley } 2000 \\
\text { (Bentley Instruments), que } \\
\text { utiliza a tecnologia do } \\
\text { infravermelho. }\end{array}$ & $\begin{array}{l}\text { Observou-se que o uso do } \\
\text { solo objetivando o cultivo } \\
\text { de grãos em detrimento } \\
\text { do pastejo animal } \\
\text { influencia negativamente } \\
\text { o teor de gordura e } \\
\text { proteína, } \\
\text { em média } 6,3 \% \text { e } 5,4 \% \text {, } \\
\text { respectivamente, } \\
\text { sobretudo no período de } \\
\text { verão. }\end{array}$ & $\begin{array}{l}\text { Santos et al. (2013) } \\
\text { Arq. Bras. Med. } \\
\text { Vet. Zootec. }\end{array}$ \\
\hline $\begin{array}{l}\text { Qualidade microbiológica } \\
\text { de leite cru refrigerado e } \\
\text { isolamento de bactérias } \\
\text { psicrotróficas } \\
\text { proteolíticas. }\end{array}$ & $\begin{array}{l}\text { Avaliar a qualidade } \\
\text { microbiológica de leite cru. }\end{array}$ & $\begin{array}{l}\text { Foram analisadas } \\
\text { amostras provenientes de } \\
\text { tanques de refrigeração } \\
\text { individual, coletivos e do } \\
\text { silo de uma indústria } \\
\text { processadora de leite. } \\
\text { Além disso, bactérias } \\
\text { psicrotróficas proteolíticas } \\
\text { foram isoladas do leite cru } \\
\text { refrigerado e } \\
\text { caracterizadas quanto à } \\
\text { reação ao Gram e } \\
\text { fermentação de glicose. }\end{array}$ & $\begin{array}{l}\text { O leite cru refrigerado } \\
\text { mantido no silo industrial } \\
\text { não atendeu ao padrão } \\
\text { microbiológico legal e } \\
\text { apresentou contagens } \\
\text { microbianas superiores às } \\
\text { do leite mantido em } \\
\text { tanques individuais ou } \\
\text { coletivos. Diferença } \\
\text { significativa na } \\
\text { contaminação por } \\
\text { mesófilos e psicrotrófilos } \\
\text { proteolíticos e não } \\
\text { proteolíticos e por } \\
\text { Pseudomonas foi } \\
\text { observada entre as } \\
\text { amostras coletadas nos } \\
\text { tanques de refrigeração e } \\
\text { no silo industrial. A } \\
\text { microbiota Gram-negativa } \\
\text { foi isolada com maior } \\
\text { frequência, } \\
\text { especialmente bactérias } \\
\text { Gram-negativas não } \\
\text { fermentadoras de glicose. }\end{array}$ & $\begin{array}{l}\text { Pinto; Marti; } \\
\text { Vanetti (2006) } \\
\text { Ciênc. Tecnol. } \\
\text { Aliment. }\end{array}$ \\
\hline
\end{tabular}




\begin{tabular}{|c|c|c|c|c|}
\hline Título & Objetivos & Metodologias & Resultados & Referência \\
\hline $\begin{array}{l}\text { Qualidade microbiológica } \\
\text { do leite refrigerado nas } \\
\text { fazendas. }\end{array}$ & $\begin{array}{l}\text { Avaliar a qualidade } \\
\text { microbiológica do leite cru } \\
\text { refrigerado, incluindo a } \\
\text { presença de patógenos de } \\
\text { interesse para a saúde do } \\
\text { consumidor, e a associação } \\
\text { entre a contaminação } \\
\text { microbiana e os procedimentos } \\
\text { de higienização dos } \\
\text { equipamentos de ordenha e } \\
\text { armazenamento } \\
\text { do leite na propriedade. }\end{array}$ & $\begin{array}{l}\text { Avaliaram-se a qualidade } \\
\text { microbiológica do leite } \\
\text { obtido mecanicamente e } \\
\text { refrigerado durante } 48 \\
\text { horas, em } 24 \text { rebanhos, e } \\
\text { a associação entre a } \\
\text { contaminação microbiana } \\
\text { e os procedimentos de } \\
\text { higienização dos } \\
\text { equipamentos de ordenha } \\
\text { e armazenamento do leite. } \\
\text { Os procedimentos de } \\
\text { higiene foram avaliados in } \\
\text { loco com auxílio de } \\
\text { questionários. Foram } \\
\text { realizadas a contagem } \\
\text { padrão em placas, a } \\
\text { contagem de coliformes } \\
\text { totais e a pesquisa de } \\
\text { Staphylococcus aureus e } \\
\text { Streptococcus agalactiae. } \\
\text { No leite de } 14 \text { rebanhos, } \\
\text { foram pesquisadas } \\
\text { Salmonella spp. e Listeria } \\
\text { monocytogenes. As } \\
\text { médias geométricas da } \\
\text { contagem padrão foram } \\
<1,0 \times 10^{6} \text { UFC/ml em } 20 \\
\text { rebanhos, e }<7,5 \times 10^{5} \\
\text { UFC/ml em } 19 .\end{array}$ & $\begin{array}{l}\text { Onze rebanhos } \\
\text { apresentaram contagem } \\
\text { média de }<1,0 \times 10^{5} \\
\text { UFC/ml. Contagens } \\
\text { médias de coliformes }>10^{3} \\
\text { UFC/ml foram verificadas } \\
\text { em sete rebanhos. S. } \\
\text { aureus e S. agalactiae } \\
\text { foram isolados em } 22 \text { e } 12 \\
\text { dos } 24 \text { rebanhos, } \\
\text { respectivamente, e não } \\
\text { foram encontradas } \\
\text { Salmonella spp. e L. } \\
\text { monocytogenes. }\end{array}$ & $\begin{array}{l}\text { Arcuri et al. (2006) } \\
\text { Arq. Bras. Med. } \\
\text { Vet. Zootec. }\end{array}$ \\
\hline $\begin{array}{l}\text { Qualidade do leite em } \\
\text { amostras } \\
\text { individuais e de tanque } \\
\text { de vacas leiteiras. }\end{array}$ & $\begin{array}{l}\text { Verificar o percentual de } \\
\text { amostras de tanque e } \\
\text { individuais dos } \\
\text { animais que atendiam aos } \\
\text { parâmetros da IN n }{ }^{\circ} 51 / 2002, \\
\text { assim como indicar qual o } \\
\text { melhor sistema de produção } \\
\text { para garantir a melhor } \\
\text { qualidade do leite, qual a } \\
\text { estação do ano com o maior } \\
\text { percentual de amostras nos } \\
\text { padrões da IN } n^{\circ} 51 \text { e se as } \\
\text { atuais análises individuais do } \\
\text { leite servem como padrão de } \\
\text { controle para melhorar a sua } \\
\text { qualidade. }\end{array}$ & $\begin{array}{l}\text { Amostras de leite foram } \\
\text { coletadas de tanques de } \\
\text { expansão ( } n=69 \text { ) e das } \\
\text { vacas individualmente ( } n= \\
\text { 3517), em propriedades } \\
\text { com sistema de produção } \\
\text { especializado (ES, } n=3 \text { ), } \\
\text { semiespecializado (SE, } n= \\
\text { 5) e não especializado (NE, } \\
n=7 \text { ). A composição, } \\
\text { contagem de células } \\
\text { somáticas (CCS) e teor de } \\
\text { nitrogênio ureico (NU) } \\
\text { foram avaliados nos } \\
\text { diferentes sistemas e } \\
\text { estações do ano. Os dados } \\
\text { foram comparados aos } \\
\text { parâmetros da Instrução } \\
\text { Normativa }{ }^{\circ} 51 / 2002 \\
\text { para a região Sul do Brasil, } \\
\text { de maio/2009 a } \\
\text { junho/2010. }\end{array}$ & $\begin{array}{l}\text { Analisando os três } \\
\text { sistemas de produção, } \\
42 \% \text { ( } n=29 / 69 \text { ) das } \\
\text { amostras de leite dos } \\
\text { tanques de expansão e } \\
11 \% \text { ( } n=375 / 3517 \text { ) das } \\
\text { individuais atenderam a } \\
\text { IN } n^{\circ} 51 . \text { Amostras de } \\
\text { leite de tanque do } \\
\text { sistema ES 70\% ( } n= \\
14 / 20 \text { ), SE } 39 \% \text { ( } n=9 / 23 \text { ) } \\
\text { e NE } 23 \% \text { ( } n=6 / 26 \text { ) } \\
\text { atenderam os critérios da } \\
\text { IN } n^{\circ} 51 . \text { Amostras de } \\
\text { leite individuais } \\
\text { apresentaram menor } \\
\text { percentual com } \\
\text { parâmetros mínimos da } \\
\text { IN } n^{\circ} 51 \text { comparada ao } \\
\text { tanque. O leite de vacas } \\
\text { sadias dilui a CCS de vacas } \\
\text { doentes, indicando que a } \\
\text { CCS do tanque não é um } \\
\text { indicador confiável para } \\
\text { qualidade do leite. Os } \\
\text { teores médios de gordura, } \\
\text { proteína e sólidos totais } \\
\text { em amostras de tanque } \\
\text { foram semelhantes entre } \\
\text { os sistemas de produção. } \\
\text { A lactose e NU nas } \\
\text { amostras do tanque } \\
\text { foram similares entre as } \\
\text { estações do ano. }\end{array}$ & $\begin{array}{l}\text { Rosa et al. (2012) } \\
\text { Arq. Inst. Biol. }\end{array}$ \\
\hline $\begin{array}{l}\text { Correlações entre } \\
\text { contagens de células } \\
\text { somáticas e parâmetros } \\
\text { físico-químicos e } \\
\text { microbiológicos de } \\
\text { qualidade do leite. }\end{array}$ & $\begin{array}{l}\text { Avaliar as correlações entre } \\
\text { contagem de células somáticas } \\
\text { (CCS) e os constituintes do leite } \\
\text { e verificar as associações das } \\
\text { condições ambientais com a } \\
\text { CCS. }\end{array}$ & $\begin{array}{l}\text { Os dados utilizados foram } \\
\text { de } 1.541 \text { unidades } \\
\text { produtoras de leite } \\
\text { referentes a } 15 \text { municípios } \\
\text { da bacia leiteira do Vale do } \\
\text { Taquari, Rio Grande do } \\
\text { Sul. Foram tabulados os } \\
\text { dados de CCS, contagem } \\
\text { bacteriana total (CBT) e } \\
\text { composição centesimal do } \\
\text { leite, referentes ao }\end{array}$ & $\begin{array}{l}\text { A temperatura ambiente } \\
\text { apresentou correlação } \\
\text { positiva e significativa } \\
\text { com a CCS, enquanto a } \\
\text { precipitação } \\
\text { pluviométrica e a } \\
\text { umidade relativa do ar, } \\
\text { ausência de correlação. } \\
\text { Os teores de gordura, } \\
\text { proteína, minerais e } \\
\text { sólidos totais foram }\end{array}$ & $\begin{array}{l}\text { Vargas et al. (2014) } \\
\text { Cienc. anim. bras. }\end{array}$ \\
\hline
\end{tabular}




\begin{tabular}{|c|c|c|c|c|}
\hline Título & Objetivos & Metodologias & Resultados & Referência \\
\hline & & $\begin{array}{l}\text { período de junho de } 2008 \\
\text { a dezembro de } 2011, \\
\text { totalizando } 44.089 \\
\text { amostras analisadas. }\end{array}$ & $\begin{array}{l}\text { diretamente } \\
\text { correlacionados com a } \\
\text { CCS, enquanto que os } \\
\text { sólidos não gordurosos e } \\
\text { a lactose apresentaram } \\
\text { comportamento inverso. } \\
\text { Por meio da análise de } \\
\text { componentes principais } \\
\text { (ACP), auxiliada pelo } \\
\text { método hierárquico } \\
\text { aglomerativo de } \\
\text { agrupamento, os sete } \\
\text { tratamentos presentes no } \\
\text { estudo foram reduzidos a } \\
\text { cinco grupos de acordo } \\
\text { com a similaridade, } \\
\text { permitindo constatar que } \\
\text { amostras com CCS } \\
\text { superiores a } 400.000 \text { até } \\
750.000 \text { céls mL } \mathrm{m}^{-1} \text {. }\end{array}$ & \\
\hline $\begin{array}{l}\text { Qualidade do leite cru } \\
\text { refrigerado sob inspeção } \\
\text { federal na região } \\
\text { Nordeste. }\end{array}$ & $\begin{array}{l}\text { Estudar a influência sazonal } \\
\text { sobre a composição química, a } \\
\text { contagem de células somáticas } \\
\text { (CCS) e a contagem bacteriana } \\
\text { total (CBT) de leite cru } \\
\text { refrigerado em vários estados } \\
\text { da região Nordeste. }\end{array}$ & $\begin{array}{l}\text { Os dados foram obtidos de } \\
116.989 \text { amostras de leite } \\
\text { de tanques coletadas pelas } \\
\text { indústrias com cadastro no } \\
\text { serviço de inspeção } \\
\text { federal. As amostras foram } \\
\text { separadas em três } \\
\text { períodos (I, II, III), de } \\
\text { acordo com aplicação da } \\
\text { Instrução Normativa } n^{\circ} 51 .\end{array}$ & $\begin{array}{l}\text { O teor de gordura, média } \\
\text { de } 3,7 \% \text {, foi o } \\
\text { componente do leite que } \\
\text { apresentou maior } \\
\text { variação. Proteína e } \\
\text { lactose tiveram amplitude } \\
\text { de } 0,04 \% \text { entre os } \\
\text { períodos e apresentaram } \\
\text { médias de } 3,2 \text { e } 4,4 \% \text {, } \\
\text { respectivamente. Maiores } \\
\text { valores de CCS foram } \\
\text { observados entre os } \\
\text { meses de maio e julho, } \\
594,33 \text { a } 625,28 \text { mil } \\
\text { cel/mL, enquanto para } \\
\text { CBT os maiores valores } \\
\text { ocorreram nos meses de } \\
\text { maio e junho, } 1308,54 \text { e } \\
1333,83 \text { UFC/mL. }\end{array}$ & $\begin{array}{l}\text { Ribeiro Neto et al. } \\
\text { (2012) } \\
\text { Arq. Bras. Med. } \\
\text { Vet. Zootec. }\end{array}$ \\
\hline
\end{tabular}

\section{DISCUSSÃO}

\section{Coleta e armazenamento}

Os processos de coleta e transporte do leite devem ser padronizados e seguindo normas legislativas aceitas internacionalmente, para que os resultados obtidos em diferentes laboratórios possam ser comparados entre si. Estes resultados auxiliam no monitoramento da sanidade da glândula mamária, determinação da qualidade pela indústria e avaliação da seguridade do leite pelos serviços de fiscalização (DIAS et al., 2012).

Os autores que obtiveram suas pesquisas selecionadas não especificaram detalhadamente os procedimentos metodológicos de coleta realizados para análise da qualidade do leite. Pinto et al. (2006), Arcuri et al. (2006), Santos et al. (2009), Citadin et al. (2009) e Vallin et al. (2009) citaram em suas pesquisas apenas que as amostras de leite foram coletadas em frascos esterilizados.

Dos artigos selecionados, sete (50\%) coletaram as amostras de leite em frascos de polietileno contendo conservante Bronopol (SOUZA et al., 2010, RIBEIRO NETO et al., 2012, SILVA et al., 2008, RIBEIRO JÚNIOR et al., 2013, SANTOS et al., 2013, ROSA et al., 2012) e o conservante Azidiol (SILVA et al., 2008; RIBEIRO JÚNIOR et al., 2013). Em todas as pesquisas as amostras foram armazenadas em caixas de isopor contendo gelo para manterem a refrigeração adequada. 
Segundo Brito et al. (2001), os conservantes são utilizados para preservação das amostras até o momento das análises em laboratório, para que não percam suas propriedades. De acordo com o autor, os frascos que possuem o conservante devem ser abertos apenas no momento da coleta e fechados imediatamente após o uso.

\section{Análises físico-químicas}

De acordo com a Instrução Normativa n 61/2011, do MAPA, as análises físico-químicas que devem ser realizadas para avaliação da qualidade do leite são determinação do índice crioscópico, teores de sólidos totais e não gordurosos (proteína e lactose), densidade relativa, acidez titulável, teor de gordura e medição da temperatura (BRASIL, 2011). A ocorrência de fraudes econômicas e o estado de conservação das amostras pode ser detectada por meio dessas análises (SILVA et al., 2008).

Nove (65\%) artigos realizaram análises físico-químicas do leite para determinação de gordura, proteína, lactose, sólidos totais e extrato seco desengordurado. Destes, sete $(78 \%)$ realizaram os ensaios descritos acima utilizando o equipamento infravermelho Bentley $2000^{\circledR}$ (RIBEIRO NETO et al., 2012; VARGAS et al., 2014; RIBEIRO JÚNIOR et al., 2013; SANTOS et al., 2013; ROSA et al., 2012; SOUZA et al., 2010). As outras duas pesquisas restantes (BRASIL et al., 2012; SANTOS et al., 2008) utilizaram em sua metodologia o equipamento infravermelho Milkoskan $4000^{\circledR}$. Devido aos avanços da tecnologia em relação à ciência dos equipamentos, tanto em aspectos toxicológicos como de identidade e qualidade, torna-se necessária a modernização e a contínua atualização de métodos analíticos (IAL, 2008).

\section{Análises microbiológicas}

Segundo a Instrução Normativa $n^{\circ}$ 62/2011, do MAPA as análises microbiológicas necessárias para serem realizadas no leite in natura são contagem bacteriana total (CBT) e contagem de células somáticas (CCS) (BRASIL, 2011). Das pesquisas selecionadas, quatro (29\%) realizaram análises de CCS e de CBT, sendo utilizados equipamentos específicos como Somacount ${ }^{\circledR}$ (CCS) e Bactocount ${ }^{\circledR}$ (CBT) (RIBEIRO JÚNIOR et al., 2013; RIBEIRO NETO et al., 2012; VALLIN et al., 2009). Santos et al. (2008) também realizaram análises de CCS e CBT, porém os autores utilizaram equipamentos diferentes, como Fotossomatic 5000 basic $^{\circledR}$ e Bactoscan $\mathrm{FC}^{\circledR}$. Todos equipamentos utilizam a metodologia de citometria de fluxo.

Quanto as análises para determinação de microrganismos mesófilos (ARCURI et al., 2006; CITADIN et al., 2009; MARTINS et al., 2013) e psicrotróficos (MARTINS et al., 2013; PINTO et al., 2006; SANTOS et al. 2009), seis (43\%) artigos afirmam realizaram as análises seguindo a metodologia de diluição decimal e plaqueamento em ágar. Os resultados foram expressos em Unidade Formadora de Colônias por $\mathrm{mL}$ de leite (UFC/mL).

Segundo Abelho (2013), a diluição decimal dilui a amostra em condições estéreis para posterior crescimento microbiano em placas de Petri. De acordo com a autora, este procedimento tem como objetivo a obtenção da diminuição da densidade celular por unidade de volume, para que desta forma, apenas algumas células sejam isoladas, posteriormente formando colônias puras. 


\section{Qualidade do leite}

A qualidade do leite pode ser influenciada por diversos fatores, dentre os quais se destacam os zootécnicos associados ao manejo, alimentação, potencial genético dos rebanhos e outros relacionados à obtenção e armazenamento do leite (MARTINS et al., 2013). A legislação brasileira estabelece condições para a obtenção e coleta do leite cru refrigerado, fixando os níveis de qualidade do leite, como requisitos físicos, químicos, microbiológicos, resíduos químicos e contagem de células somáticas (CCS) (SANTOS et al., 2008).

Por sua composição, o leite é considerado um dos alimentos mais completos em termos nutricionais e fundamentais para dieta humana, mas pela mesma razão, constitui como um excelente substrato para o desenvolvimento de uma grande diversidade de micro-organismos, inclusive os patogênicos (SILVA et al., 2008). São realizados diversos testes para avaliar a qualidade do leite cru seguindo os regulamentos do MAPA. De modo geral, as características físico-químicas e sensoriais como sabor e odor são definidos. Parâmetros como os de baixa contagem de bactérias e de CCS, ausência de micro-organismos patogênicos e de conservantes químicos, entre outros (BRASIL, 2011).

Para a manutenção da qualidade do leite cru refrigerado devem ser tomadas medidas preventivas como higiene adequada na ordenha, limpeza e sanitização dos equipamentos do tanque de refrigeração, resfriamento do leite logo após a ordenha, manutenção da temperatura baixa até o momento do processamento térmico e a estocagem do leite por um tempo não muito longo para não favorecer a multiplicação de micro-organismos (SANTOS et al., 2009; BRASIL, 2017).

Cinco (36\%) artigos constataram que a qualidade do leite poderia estar relacionada a diversos fatores, dentre os quais a refrigeração (LANGONI, et al., 2011), a alimentação animal, o potencial genético dos rebanhos e o armazenamento do leite (MARTINS et al., 2013). Santos et al. (2013) comentaram que o uso do solo também pode interferir na qualidade do leite. Vallin et al. (2009) descreveram que a má qualidade do leite está relacionada com fatores de deficiência no manejo e higiene da ordenha, índice elevado de mastite, manutenção e desinfecção inadequados dos equipamentos e a mão de obra desqualificada. Citadin et al. (2009) ressaltaram que a lavagem dos utensílios, utilização de água quente e de luvas, entre outros fatores, podem proporcionar aumento na qualidade do leite.

\section{Qualidade microbiológica}

As características das bactérias presentes no leite devem ser examinadas por vários aspectos: as deteriorantes, patogênicas, indicadoras e benéficas. A ação deteriorante das bactérias consiste em metabolizar a lactose e produzindo-se assim ácido lático, causando a diminuição do pH (ORDÓÑEZ, 2005). As bactérias prejudiciais do leite provocam transformações indesejadas pela indústria, como modificações de cor e sabor do leite, coagulação e decomposição de proteínas (CARVALHO, 2010).

Os microrganismos contaminantes do leite podem ser divididos em três grupos principais: os mesófilos, que se multiplicam rapidamente quando o leite não é armazenado sob refrigeração, os termodúricos que sobrevivem à pasteurização e os psicrotróficos, que se multiplicam em temperaturas 
baixas (SANTOS et al., 2013). As bactérias mesófilas possuem ação patogênica no leite. Já as bactérias psicrotróficas possuem ação deteriorante no material proteico e lipídico do leite, mesmo após o mesmo ter passado por processos para se tornarem derivados (ORDÓÑEZ, 2005).

Devido ao tempo de armazenamento e a coleta à granel, o processo de análise do leite acontece somente alguns dias depois da ordenha, em alguns casos. Este período de estocagem sob refrigeração, ou deficiência da mesma, associado à falta de higiene antes, durante e depois da ordenha, aumenta o desenvolvimento do número de microrganismos (BRITO et al., 2007).

Das pesquisas realizadas, apenas Martins et al. (2013) realizaram as análises para contagem de mesófilos e psicrotróficos, sendo que os resultados encontrados na pesquisa não estavam de acordo com a Instrução Normativa n 62/2011 (MAPA), que permite 6,0 × $10^{5} \mathrm{UFC} / \mathrm{mL}$ de mesófilos. Para os psicrotróficos, não há legislação vigente, uma possibilidade seria utilizar os autores Nörnberg et al. (2009), que realizaram estudos, e constataram que não é aconselhável a comercialização do lácteo com valores maiores do que $1 \mathrm{x}$ $10^{6} \mathrm{UFC} / \mathrm{mL}$. Mörschbächer et al. (2017) analisaram a qualidade microbiológica do leite cru presente na propriedade leiteira e após o transporte para a indústria beneficiadora, através da contagem em placas de microrganismos mesófilos e psicrotróficos e também constataram que nas amostras coletadas diretamente nos tanques das propriedades, a média de microrganismos mesófilos foi mais alta do que a amostra coletada diretamente do caminhão de transporte ao chegar à indústria. Dos 14 tanques amostrados, 64,3\% estavam em desacordo com a legislação e a amostra coletada do caminhão de transporte do leite, contendo o leite de todas as propriedades, apresentou uma média maior de microrganismos psicrotróficos em relação à média das propriedades.

Santos et al. (2009) e Pinto et al. (2006) realizaram pesquisas apenas para contagem de microorganismos psicrotróficos, sendo que ambos os estudos obtiveram resultados considerados em desacordo com a literatura consultada pelos autores. Os autores também relacionaram os resultados obtidos devido à falta de higiene durante a ordenha. Citadin et al. (2009) e Arcuri et al. (2006), que realizaram suas pesquisas somente com micro-organismos mesófilos, também obtiveram seus resultados em desacordo com a legislação.

Constatou-se que, dos 14 artigos avaliados, nove (64\%) basearam suas pesquisas microbiológicas em contagem de células somáticas (CCS) (BRASIL et al., 2012; RIBEIRO JÚNIOR et al., 2013; MARTINS et al., 2013; RIBEIRO NETO et al., 2012; ROSA et al., 2012; SANTOS et al., 2008; SANTOS et al., 2009; SOUZA et al., 2010; VALLIN et al., 2009;). Vargas et al. (2014) concluíram que o aumento das células somáticas está relacionado com o aumento dos teores de gordura, proteínas e sólidos totais, e a diminuição dos teores de lactose e sólidos não gordurosos.

Nos artigos de Rosa et al. (2012), Vargas et al. (2014) e Ribeiro Neto et al. (2012) os resultados das amostras de leite estiveram em desacordo com a IN 62/2011, representando 33\% das pesquisas realizadas relacionadas às CCS, o restante das pesquisas obteve-se de acordo com o padrão vigente. Apenas um (8\%) artigo não realizou análises microbiológicas (SANTOS et al., 2013). 
As quantidades de CCS no leite indicam inflamação da glândula mamária da vaca, que pode ser causado por bactérias. Sua variação também pode interferir na composição química do leite. Estes fatores diminuem significativamente as produções de leite de qualidade, interferindo na economia das propriedades leiteiras (BRITO et al., 2007).

\section{Qualidade físico-química}

Segundo Zocche et al. (2002), a importância das análises físico-químicas consiste na detecção de fraudes, como adição de água, desnate, superaquecimento, entre outros compostos. Analisando-se os artigos, constatou-se que cinco (36\%) pesquisas se basearam em análises de gordura, proteína e extrato seco desengordurado. Santos et al. (2013) constataram que os parâmetros analisados variam de acordo com o uso de solo (plantação e pastagem). Martins et al. (2013) e Souza et al. (2010) tiveram os seus resultados considerados de acordo com a respectiva legislação.

Já Santos et al. (2008) analisaram a qualidade físico-química em diferentes períodos de estocagem, e concluíram que, de acordo com a legislação, as amostras não apresentaram valores dentro do padrão estabelecido. Este fator pode ser influenciado pela raça, manejo, clima e nutrição. Ribeiro Neto et al. (2012) também encontraram resultados fora dos parâmetros estabelecidos. Outro fator que influencia nestes parâmetros é a contagem de células somáticas, no qual seu aumento pode influenciar nos valores de gordura, proteína e extrato seco desengordurado (VARGAS, 2014).

Santos et al. (2009) realizaram análises para avaliação da acidez do leite, no qual seus resultados estavam de acordo com a respectiva legislação. O leite já se apresenta ácido no momento da ordenha, porém pode aumentar a acidez dependendo do tempo em que é estocado, este fator é causado pelos microorganismos presentes no leite, a temperatura do refrigerador e a falta de higiene com o mesmo (SANTOS et al., 2009).

A pesquisa de Ribeiro Júnior et al. (2013) também realizaram análises de acidez, juntamente com análises de densidade e índice crioscópico, ambas análises se apresentaram fora dos parâmetros estabelecidos. $\mathrm{O}$ autor constatou que as amostras podiam estar possivelmente fraudadas por adição de água. A crioscopia do leite apresenta variação muito pequena, mas pode ocorrer dependendo das modificações da dieta alimentar do rebanho, período de lactação do animal, estação do ano, ou até mesmo como fraude por adição de água. Esta adição pode alterar os valores do índice crioscópico (TRONCO, 2003).

\section{CONCLUSÃO}

Dos 1.743 artigos entrados nas bases de dados utilizadas, 14 destas apresentavam pesquisas de interesse sobre a qualidade físico-química e microbiológica do leite in natura, bem como metodologias de análise, coletas aplicadas e resultados obtidos. Do total de artigos de interesse (14), 11 (79\%) pesquisas apresentaram resultados da qualidade do leite ineficazes, devido à falta higiênico-sanitária, estação do ano, procedimentos de armazenamento ou período de lactação. Dos 14 artigos, cinco apresentaram os resultados 
das análises de acordo com a legislação vigente. Todos artigos selecionados apresentaram metodologias de análise e coletas semelhantes às estudadas.

A implantação de boas práticas de higiene na ordenha visa a obtenção de leite cru refrigerado de boa qualidade, tendo um papel importante para garantir o bem-estar animal, uma melhor qualidade do leite produzido, maior lucratividade para o produtor e a sustentabilidade da produção. Vale ressaltar que esta pesquisa apresenta limitações quanto aos resultados obtido em cada artigo selecionado, sendo divulgado apenas os principais dados de interesse para este artigo. Para uma melhor compreensão da pesquisa realizada pelos artigos, recomenda-se a leitura completa dos mesmos.

\section{REFERÊNCIAS}

ABELHO, M.. Protocolos de microbiologia ambiental Parte 1 Métodos Básicos em Microbiologia. Coimbra: Escola Superior Agrária, 2013.

ARCURI, E. F.; BRITO, M. A. V. P.; BRITO J. R. F.; PINTO, S. M.; ÂNGELO, F. F.; SOUZA, G. N.. Qualidade microbiológica do leite refrigerado nas fazendas. Arquivo Brasileiro de Medicina Veterinária e Zootecnia, v.58, n.3, p.440-446, 2006. DOI: http://dx.doi.org/10.1590/S0102$\underline{09352006000300024}$

BRASIL, R. B.; SILVA, M. A. P.; CARVALHO, T. S.; CABRAL, J. F.; NICOLAU, E. S.; NEVES, R. B. S.. Avaliação da qualidade do leite cru em função do tipo de ordenha e das condições de transporte e armazenamento. Revista do Instituto de Laticínios Cândido Tostes, n.389, v.67, p.34-42, 2012. DOI:http://dx.doi.org/10.5935/2238-6416.20120076

BRASIL. Instrução Normativa $\mathbf{n}^{\circ} \mathbf{5 1}$ de $\mathbf{2 0}$ de setembro de 2002. Aprova os regulamentos técnicos de produção, identidade e qualidade do leite tipo. Ministério da Agricultura, Pecuária e Abastecimento (MAPA). Brasília: Diário Oficial da União, 2002.

BRASIL. Instrução Normativa $\mathbf{n}^{\circ} \mathbf{6 2}$ de $\mathbf{2 9}$ de dezembro de 2011. Aprova o regulamento técnico de produção, identidade e qualidade do leite tipo. Ministério da Agricultura, Pecuária e Abastecimento (MAPA). Brasília: Diário Oficial da União, 2011.

BRASIL. Decreto $\mathbf{9 . 0 1 3}$ de 29 de março de 2017. Dispõe sobre a inspeção industrial e sanitária de produtos de origem animal. Brasília: Diário Oficial da União, 2017.

BRITO, J. R. F.. Coleta de amostras de leite para determinação da composição química e contagem de células somáticas. EMBRAPA Gado de Leite, Juiz de Fora, p.15, 2001.

BRITO, J. R. F.. Células somáticas no leite. Agência de Informação Embrapa. In: BRITO, M. A.; BRITO, J. R.; ARCURI E.; LANGE, C.; SILVA, M.; SOUZA, G.. Tipos de Microorganismos. Agência de Informação Embrapa. 2007.

CARVALHO, I. T.. Microbiologia de alimentos. Programa Escola Técnica Aberta do Brasil (ETEC). Recife: ETEC, 2010.

CITADIN, A. S.; POZZA, M. S.S; POZZA, P. C; NUNES, R. V.; BORSATTI, L.; MANGONI, J.. Qualidade microbiológica de leite cru refrigerado e fatores associados. Revista Brasileira de Saúde e Produção Animal, v.10, n.1, p.52-59, 2009.

DIAS, J. A.; ANTES, F. G.. Procedimentos para a coleta de amostras de leite para a contagem de células somáticas, contagem bacteriana total e detecção de resíduos de antibiótico. Porto Velho: EMBRAPA, 2012.

IBGE. Instituto Brasileiro de Geografia e Estatística. PPM: Rebanho bovino alcança a marca recorde de 215,2 milhões de cabeças, mas produção de leite cai 0,4\%. Estatísticas Econômicas. 2016.

IAL. Instituto Adolfo Lutz. Métodos físico-químicos para análise de alimentos. São Paulo: Secretaria de Estado da Saúde, 2008

LANGONI, H.; PENACHIO, D. S.; CITADELLA, J. C. C.; LAURINO, F.; FACCIOLI-MARTINS, P. Y.; LUCHEIS, S. B.; MENOZZI, B. D.; SILVA, A. V.. Aspectos microbiológicos e de qualidade do leite bovino. Pesquisa Veterinária Brasileira, v.31, n.12, p.1059-1065, 2011. DOI: http://dx.doi.org/10.1590/S0100736X2011001200004.

LEITE, A. F. S.; TORRANO, A. D. M.; GELLI, D. S.. Qualidade microbiológica do leite tipo $C$ pasteurizado, comercializado em João Pessoa, Paraíba. Revista Higiene Alimentar, São Paulo, v.14, n. 4, p.45-49, 2000.

MARTINS, M. L.; CARVALHAES, J. F.; SANTOS, L. J.; MENDES, N. S.; MARTINS, E. M. F.; MOREIRA, G. I. P.. Qualidade do leite cru dos tanques de expansão individuais e coletivos de um laticínio do município de Rio Pomba, MG - um estudo de caso. Revista do Instituto de Laticínios Cândido Tostes, v.68, n.392, p. 24-32, 2013.DOI: http://dx.doi.org/10.5935/2238$\underline{6416.20130025}$

MÖRSCHBÄCHER, V. K.; REMPEL, C.; MACIEL, M. J. Microbiological quality of refrigerated raw milk in the dairy farm and after transport to the processing dairy plant. Arquivos do Instituto Biológico, São Paulo, 2017.

NÖRNBERG, M. F. B. L.; TONDO, E. C.; BRANDELLI, A.. Bactérias psicrotróficas e atividade proteolítica no leite cru refrigerado. Acta Scientiae Veterinariae, v.37, n.2, p.157163, 2009.

ORDÓÑEZ, J. A.. Tecnologia de alimentos: alimentos de origem animal. Porto Alegre: Artmed, 2005. 
PINTO, C. L. O.; MARTINS, M. L.; VENETTI, M. C. D.. Qualidade microbiológica de leite cru refrigerado e isolamento de bactérias psicrotróficas proteolíticas. Ciências e Tecnologia de Alimentos, v.26, v.3, p.645-651, 2006. DOI: http://dx.doi.org/10.1590/S0101-20612006000300025

RIBEIRO JÚNIOR, J. C.; BELOTI, V.; SILVA, L. C. C.; TAMANINI, R.. Avaliação da qualidade microbiológica e físico-química do leite cru refrigerado produzido na região de Ivaiporã, Paraná. Revista do Instituto de Laticínios Cândido Tostes, v.68, n.392, p.5-11, 2013. DOI: http://dx.doi.org/10.5935/2238-6416.20130022

RIBEIRO NETO, A. C.; BARBOSA, S. B. P.; JATOBÁ, R. B.; SILVA, A. M.; SILVA, C. X.; SILVA, M. J. A.; SANTORO, K. R..

Qualidade do leite cru refrigerado sob inspeção federal na região Nordeste. Arquivo Brasileiro Medicina Veterinária e Zootecnia, v.64, n.5, p.1343-1351, 2012.

ROSA, D. C.; TRENTIN, J. M.; PESSOA, G. A.; SILVA, C. A. M.; RUBIN, M. I. B.. Qualidade do leite em amostras individuais e de tanques de vacas leiteiras. Arquivos do Instituto Biológico, São Paulo, v.79, n.4, p.485-493, 2012. DOI: http://dx.doi.org/10.1590/S1808-16572012000400004

SANTOS, D. B.; VANINI, J.; SILVA, C. G.; BONDAN, C.; BORTOLUZZI, E. C.. Qualidade do leite de propriedades familiares praticantes de integração lavoura-pecuária em função do uso do solo. Arquivo Brasileiro de Medicinas Veterinárias e Zootecnia, v.65, n.4, p.1217-1222, 2013. DOI: http://dx.doi.org/10.1590/S0102-09352013000400038

SANTOS, P. A.; SILVA, M. A. P.; ANASTÁCIO, P. I. B.; JÚNIOR, H. A. S., SILVA, J. W.; NICOLAU, E. S.. Avaliação do tempo de armazenamento sobre parâmetros de qualidade do leite cru refrigerado. Revista do Instituto de Laticínios Cândido Tostes, v.64, n.367/368, p.35-41, 2009.

SANTOS, P. A.; SILVA, M. A. P.; ANASTÁCIO, P. I. B.; JÚNIOR, L. C. S.; ISEPON, J. S.; NICOLAU, E. S.. Qualidade do leite cru refrigerado estocado por diferentes períodos. Revista do Instituto de Laticínios Cândido Tostes, v.364, n.63, p.36-41, 2008.

SILVA, M. A. P.. Influência dos tipos de ordenha, transporte e tempo de armazenamento na qualidade do leite cru refrigerado da região sudoeste do Estado de Goiás. Tese (Doutorado em Veterinária) - Universidade Federal de Goiás, Goiânia, 2008.

SILVA, M. C. D.; SILVA, J. V. L.; RAMOS, A. C. S.; MELO, R. O.; OLIVEIRA, J. O.. Caracterização microbiológica e físicoquímica de leite pasteurizado destinado ao programa do leite no Estado de Alagoas. Sociedade Brasileira de Ciência e Tecnologia de Alimentos, v.28, n.1, p.226-230, 2008. DOI: http://dx.doi.org/10.1590/S0101-20612008000100032.

SOUZA, R.; SANTOS, G. T.; VALOTTO, A. A.; SANTOS, A. L.; GASPARINO, E.; SILVA, D. C.; SANTOS, W. B. R.. Produção e qualidade do leite de vacas da raça Holandesa em função da estação do ano e ordem de parto. Revista Brasileira de Saúde e Produção Animal, v.11, n.2, p.484-495, 2010.

TIMM, C. D.; GONZALEZ, H. L.; OLIVEIRA, D. S.; BUCHLE, J.; ALEXIS, M. A.; COLEHO, F. J. O; PORTO, C.. Avaliação da qualidade microbiológica do leite pasteurizado integral, produzido em micro- usinas da região sul do Rio Grande do Sul. Revista Higiene Alimentar, São Paulo, v.17, n.106, p.100-104, 2003.

TRONCO, V. M.. Manual para Inspeção da Qualidade do Leite. 2 ed. Santa Maria: UFSM, 2003.

VALLIN, V. M.; BELOTI, V.; BATTAGLINI, A. P. P.; TAMININI, R.; FAGNANINI, R.; ANGELA, H. L.; SILVA, L. C. C.. Melhoria da qualidade do leite a partir da implantação de boas práticas de higiene na ordenha em 19 municípios da região central do Paraná. Semina: Ciências Agrárias, Londrina, v.30, n.1, p.181-188, 2009. DOI: httP://10.5433/16790359.2009v30n1p181

VARGAS, P. V.; NÖRNBERG, J. L.; MELLO, R. O.; SHEIBLER, R. B.; BREDA, F. C.; MILANI, M. P.. Correlação entre contagem de células somáticas e parâmetros físico-químicos e microbiológicos de qualidade do leite. Ciência Animal Brasileira, v.15, n.4, p.473-483, 2014. DOI: http://10.590/1809-6891v15i420637

ZOCCHE, F.; BERSOT, L. S BARCELLOS, V. C.; PARANHOS, J. K.; ROSA, S. T. M.; RAYMUNDO, N. K.. Qualidade microbiológica e físico-química do leite pasteurizado produzido na região oeste do Paraná. Archives of Veterinary Science, v.7, n.2, p.59-67, 2002. DOI: http://dx.doi.org/10.5380/avs.v7i2.3982

A CBPC - Companhia Brasileira de Produção Científica (CNPJ: 11.221.422/0001-03) detém os direitos materiais desta publicação. Os direitos referem-se à publicação do trabalho em qualquer parte do mundo, incluindo os direitos às renovações, expansões e disseminações da contribuição, bem como outros direitos subsidiários. Todos os trabalhos publicados eletronicamente poderão posteriormente ser publicados em coletâneas impressas sob coordenação da Sustenere Publishing, da Companhia Brasileira de Produção Científica e seus parceiros autorizados. Os (as) autores (as) preservam os direitos autorais, mas não têm permissão para a publicação da contribuição em outro meio, impresso ou digital, em português ou em tradução. 